\title{
Seasonal and long-term changes in fishing depth of Lake Constance whitefish
}

\author{
G. THOMAS \\ Limnological Institute, University of Konstanz, Konstanz, Germany
}

R. RÖSCH

Fishery Research Station Baden-Württemberg, Langenargen, Germany

\author{
R. ECKMANN
}

Limnological Institute, University of Konstanz, Konstanz, Germany

\begin{abstract}
The ecosystem of Lake Constance in central Europe has undergone profound modifications over the last six decades. Seasonal and inter-annual changes in the vertical distribution patterns of whitefish were examined and related to changes in biotic and abiotic gradients. Between 1958 and 2007, the average fishing depth in late summer and autumn was related to two factors influencing food supply of whitefish - lake productivity and standing stock biomass. In years with low food supply, whitefish were harvested from greater depths, where temperatures were up to $4{ }^{\circ} \mathrm{C}$ lower. The whitefish's distribution towards colder water might be a bioenergetic optimisation behaviour whereby fish reduce metabolic losses at lower temperatures, or it may result from a reassessment of habitat preference under conditions of limited food supply, according to the ideal free distribution theory.
\end{abstract}

KEYWORDS: eutrophication, ideal free distribution, intraspecific competition, reoligotrophication, vertical distribution.

\section{Introduction}

The horizontal and vertical distribution patterns of pelagic fish are shaped by abiotic and biotic environmental gradients. In small- and medium-sized lakes (unlike large lakes and marine systems), these gradients tend to be more pronounced in the vertical plane than in the horizontal. Abiotic factors influencing the vertical distribution of fish include temperature, oxygen concentration and light (Rudstam \& Magnuson 1985; Fernöa et al. 1995; Aksnes et al. 2004), while the main biotic factors are the distributions of predators and prey organisms (Mittelbach 1981; Werner et al. 1983; Werner \& Hall 1988). The ideal free distribution theory (Fretwell 1972) predicts that individuals of an animal population should distribute along a resource gradient in proportion to availability of the resource. If the animals' distribution is indeed free, then other factors such as predation risk can be expected to vary predictably with changes in the spatio-temporal patterns of resource availability.

By comparing repeated changes and/or long-term trends in the distribution of an animal population with variations in resource availability, it is possible to analyse the relative importance of individual environmental factors influencing the distribution and migration patterns of a population. The present study used this approach to examine the influence of abiotic and biotic factors on the vertical distribution of pelagic coregonids in Lake Constance over a 50 -year period.

The past 50 years have seen considerable changes in environmental conditions in Lake Constance (Bäuerle $\&$ Gaedke 1998). Anthropogenic eutrophication began in the 1950 s and had profound effects on both abiotic 
and biotic aspects of the lake's ecology. Increased nutrient input promoted algal growth, which in turn influenced other characteristics, including the subsurface light penetration and the structure and function of the lake food webs. These changes, and the subsequent period of re-oligotrophication, make the last six decades particularly suitable for studying the influence of resource availability on the vertical distribution of fish.

Variations in fish community composition or in the abundance, growth or distribution patterns of particular species seldom pass unnoticed, particularly in lakes where professional fisheries and angling play an important role, as is the case in Lake Constance. The ecological knowledge of professional fishers has thus far been a largely neglected resource, while angler catch data have been used for many decades (Arlinghaus et al. 2002). Mackinson (2001) highlighted the advantages of combining such local information with scientific data. In contrast to research surveys, the efforts of fishers are continuous and long-term. Thus the experience of fishers is a valuable source of information for scientists. Falling back on fishers' knowledge is often the only way of gaining information from the past. Inevitably the reliability and accuracy with which such information is documented varies and may limit its usefulness. For Lake Constance, however, data regarding the practices of the professional fishers are summarised in monthly reports produced by fishery wardens. These reports are an invaluable resource extending back to the 1950 s, and complement longterm fisheries statistics and monitoring data.

This study focuses on seasonal and long-term changes of the vertical distribution of whitefish, Coregonus lavaretus (L.), in Lake Constance. Information documented by fishery wardens regarding the depth of pelagic gillnet fishing was considered a measure of fish vertical distribution (Horak \& Tanner 1964), and Rösch (2003) showed that fishing depth in summer and autumn increased year on year between 1990 and 2003. This study was expanded to the years 1958 to 2007 , and the relationship between fishing depth and various environmental factors both within and between years was analysed.

\section{Material and methods}

\section{Lake Constance}

Lake Constance is a large pre-alpine lake in Europe situated at the southern boarder of Germany, and is shared by Austria, Germany and Switzerland. It is an on-line lake on the River Rhine formed naturally during the last ice age. The lake comprises two basins with differing morphology. Lower Lake Constance has a surface area of $63 \mathrm{~km}^{2}$ and a mean depth of $13 \mathrm{~m}$, while Upper Lake Constance (ULC) has a surface area of $473 \mathrm{~km}^{2}$ and a maximum depth of $254 \mathrm{~m}$. Upper Lake Constance is managed jointly by Austria, Germany and Switzerland (Internationale Gewässerschutzkomission für den Bodensee, IGKB).

\section{Fishing practice}

About 150 professional fishers operate the commercial gillnet fishery in ULC. In the last 15 years, whitefish has contributed up to $80 \%$ of total fish harvest and is therefore of economic interest. Perch, Perca fluviatilis L. ranks second in the commercial fishery, contributing $14.5 \%$ of the total harvest in 2003 . Since 1954, drifting nylon gillnets began to replace existing gears used to catch whitefish in the pelagic zone, and by the end of the 1950s became the sole means of harvesting this species. The efficiency of nylon gillnets led to an intensification of the fishing effort and in the early 1960s, it became apparent that whitefish stocks were being overharvested (Nümann 1964). Consequently, in 1963, the minimum knot to knot mesh-size was raised from $38 / 40$ to $44 \mathrm{~mm}$. In addition to fixed mesh-size, fishing was strictly regulated by number of nets per licence, fishing days per week, overall size of gillnets and establishment of a closed season. Compliance with these regulations has been enforced by fishery wardens since the 1950s. Among the six wardens working at ULC, two are employed by the federal state of BadenWürttemberg, one for the eastern and one for the western part of the lake. Both wardens compile monthly reports on fishery-relevant data, such as the location of the core fishing area, average monthly harvests, average fishing depth, as well as additional information on special circumstances, e.g. meteorological events. Fishing depth is recorded as the length of the droplines by which the float lines of pelagic gillnets are attached to surface floats. As gillnets are $7 \mathrm{~m}$ high, fishing depth indicates the upper limit of the $7 \mathrm{~m}$ deep zone in which fish will be caught.

\section{Data collection}

Reports on whitefish catches for the western part of ULC exist since 1975 and for the eastern since 1956. Both lake parts differ slightly in several abiotic variables, which can be attributed to the River Rhine entering the lake at the easternmost end. Therefore, the possibility that seasonal variations in zooplankton abundance or temperature may differ between the two 
parts of the lake cannot be excluded. This likelihood is supported by the fishery not being spread evenly across the lake during the year. For this reason, data from just one area, the eastern part of ULC, were used to analyse changes in fishing depth over time. Given the 50-year timescale of the study, responsibility for control of the fishery, and thus for documenting the associated data, have passed from person to person, and there is variation in the quality of data over time. Data pertaining to variables such as location of the core fishing zone, net depth and average yield per fisher were recorded regularly but not necessarily documented for every month of every year. Data for the 1950 s are often lacking, while in subsequent decades information on fishing depth is rather well documented, although the nature of the records varies. Sometimes net depth was given in metres, sometimes in Klafter, an approximate local unit of measurement equivalent to the distance between both hands with outstretched arms. For the analysis, one Klafter was converted to $1.7 \mathrm{~m}$. Not all fishers fish with the same dropline length on the same day. The way in which this variability was documented differed between reports. In some reports, both minimum and maximum fishing depths were given, while in others, the mean depth was reported without any information regarding spread. Whenever fishing depths reported for a particular month varied, a mean depth was calculated for the purpose of the current analyses.

Raw data were extracted from the wardens' reports. As fishing depth can change considerably within a month, average values were calculated for the first and second half of each month. When only one depth was reported for the entire month, this value was used for both data points. The resulting data set covered the years 1958-2007.

Surface temperature data for the years 1961-2006 and Secchi depth data from 1974 to 2005 for the central part of ULC were obtained from the Institute for Lake Research at Langenargen and assigned to the same time grid as the fishing depth data. Averages for phosphorous concentration during spring turnover were obtained from the IGKB report 2009 for the most recent years. Values for average annual standing stock biomass of whitefish were taken from Thomas and Eckmann (2007).

To study the influence of temperature on the vertical distribution of lake whitefish, September fishing depths and vertical temperature profiles were plotted for the years 1961-2006. As only one temperature profile and two data points for fishing depth were available per month, months in which temperature gradients change continuously were not suitable for this analysis.
September was chosen because it represents a relatively stable period for both fish and temperature profiles.

\section{Statistical analysis}

For the analysis of long-term trends in fishing depth, data were merged into five decades. Each decade comprised 18 data points, two data points for each month of the fishing season (from the 2 nd half of January until the 1st half of October). Since fishing is restricted to below the surface upper $2 \mathrm{~m}$ during April and May, only data from 1 June onwards were used. Fishing depth was correlated with the factors decade and course of the year using a general linear model (GLM). In a second step, differences in fishing depth between decades were tested with a post hoc Student ' $t$ '-test.

The influence of environmental factors on fishing depth was analysed separately for each of the 18 time bins for the study period (1958-2007) using multiple linear regression models. For each time bin, fishing depth was regressed against phosphorus concentration during spring turnover, the natural logarithm of whitefish standing stock biomass and Secchi depth. The additional variable year was included to account for possible trends in fishing depth across time not accounted for by the aforementioned variables.

\section{Results}

A consistent pattern in fishing depth was found across all years during the study period (Fig. 1). Whitefish were fished from depths of 20-35 $\mathrm{m}$ from the beginning

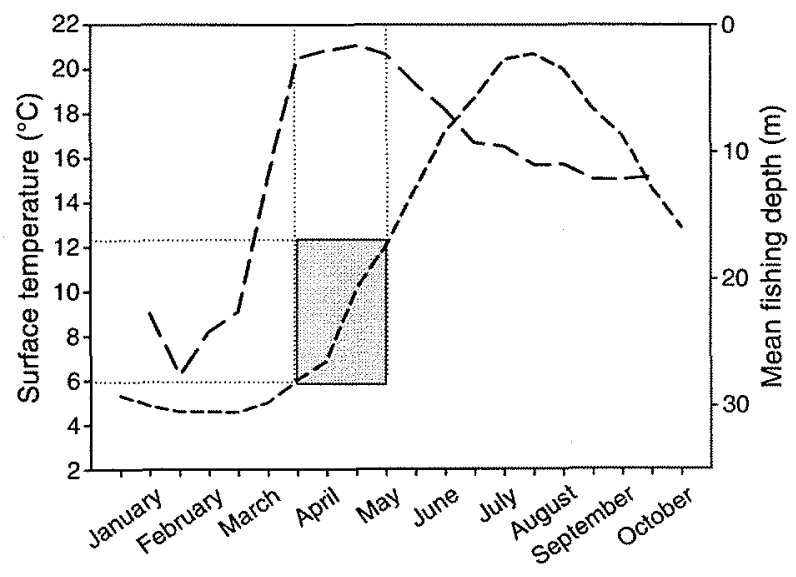

Figure 1. Seasonal changes in average fishing depth (float line of gillnets) between 1958 and 2007 (long dashed line) and surface water temperature in ULC (short dashed line) between 1963 and 2007. The grey box displays the temperature range to which whitefish are exposed when they are close to the surface in April/May 
of the year until the end of February. In March, whitefish ascend to the surface and by early April, fish are caught close to the surface. The most effective fishing depth was immediately below the surface, but because of ship traffic, a minimum net depth of $2 \mathrm{~m}$ is imposed. Gillnets are set close to this upper limit during April and May, after which whitefish begin to descend once again to greater depths. The downward shift is normally completed by the beginning of September when dropline length varies between 9 and $17 \mathrm{~m}$. Allowing for $7-\mathrm{m}$ net height, this indicates the densest aggregations of fish were between 9 and $16 \mathrm{~m}$, and 17 and $24 \mathrm{~m}$.

The progressive downward shift in fishing depth during summer varied between months and between decades (Fig. 2). Fishing depth was significantly (GLM; $\quad P<0.0001$ ) related to both decade $(F=24.8)$ and period of the year $(F=135.8)$, while the interaction between the latter two factors was not significant $(P=0.827)$. Fishing depth also differed significantly between all decades, with the exception of the decade 1968-1977 ( $t$-test, $P<0.05$ ).

By the end of the fishing season in early October, fish were distributed between 8.9 and $15.9 \mathrm{~m}$ on average between 1978 and 1987, but were caught between 15.2 and $22.2 \mathrm{~m}$ in the period 1998-2007. Although the nets are set overnight, when whitefish may range widely in the vertical plane, fishing depth data most likely corresponded to the dusk/dawn distribution of whitefish, since capture probability was highest in the crepuscular hours when fish foraging activity is highest (Becker \& Eckmann 1992).

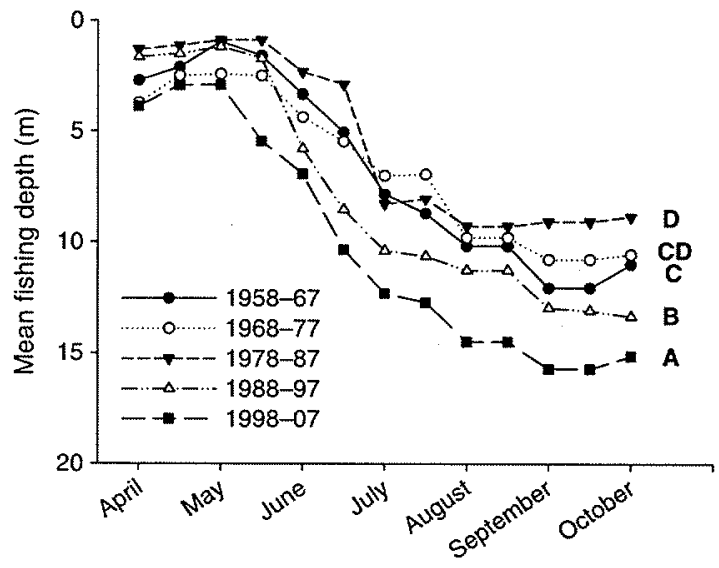

Figure 2. Changes in mean fishing depth (float line of gillnets) from April until the end of October. The five decades, comprising the years 1958-2007, differ in the amplitude of the seasonal downward migration. Capital letters indicate decades that differ significantly (post hoc test, $P<0.05$ ). Note: the decade 1968-1977 did not differ significantly from the neighbouring ones.
Fishing depth was significantly related to year in the 1 st and 2nd half of February (Fig. 3b). This result should be treated with caution, as fishing depth might be uncoupled from the fish's vertical distribution during this time of the year. Fishery harvests during late winter and early spring are minimal (approx. 5-10\% of total annual harvest is obtained from January to March). These low capture rates provide insufficient feedback for accurate gauging of the vertical fish density gradient and the gains to be made by altering fishing depth are slight. Furthermore, between 10 January and 31 March gillnets are anchored, making any adjustment more laborious. Therefore, nets are checked less often (every second day), and moved to a different depth even less frequently. In April and May, fishing depth was not correlated to year or to any of the environmental variables considered.

During the second half of the fishing season, lake productivity (represented by phosphorous con-

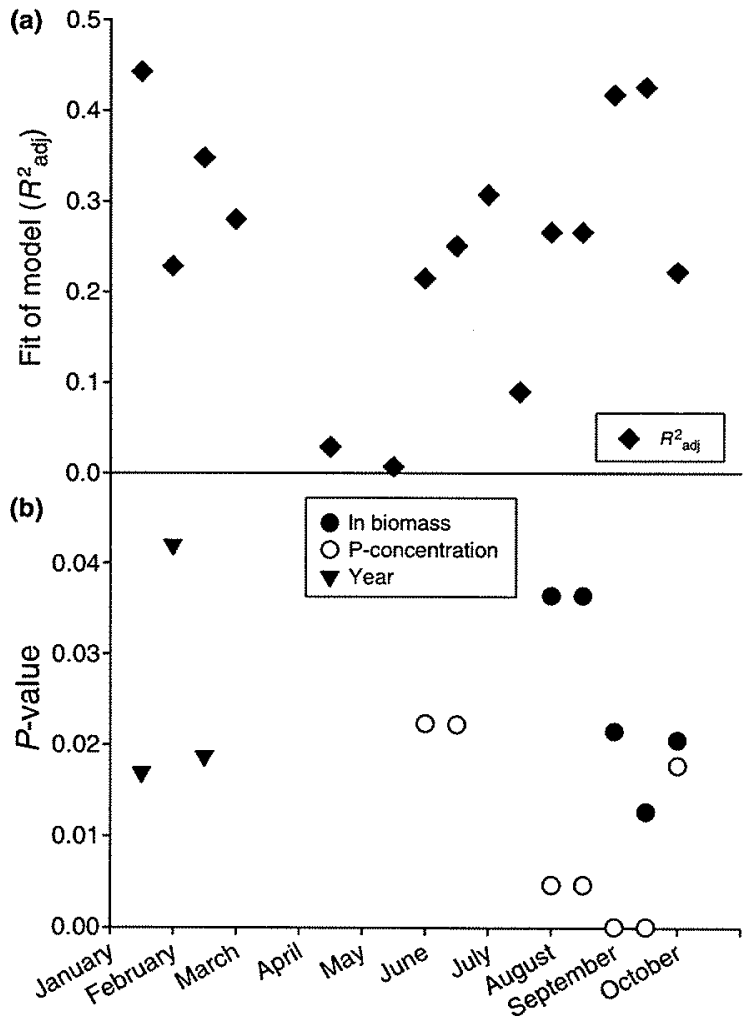

Figure 3. Model output from multiple linear regression analyses of fishing depth vs phosphorus concentration, standing stock biomass and year. (a) The overall model fit $\left(R_{\text {adj }}^{2}\right)$ is nearly zero when fish stay close to the surface in April and May but increases continuously towards autumn. (b) $P$-values for the independent factors are indicated when they are lower than 0.05 . 


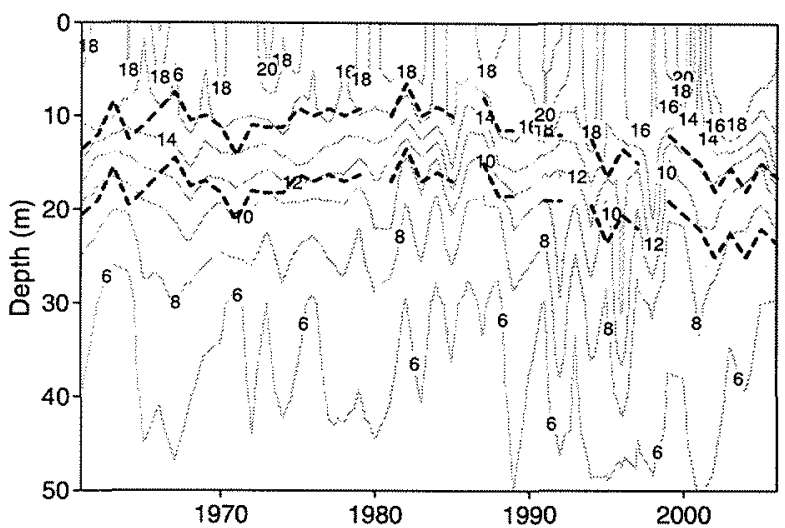

Figure 4. Temperature in the depth layer from which whitefish were harvested in September between 1961 and 2006. Isotherms are shown as grey lines. Fishing depth layer is delimited by dashed black lines (upper line is float line depth, lower line is lead line depth, i.e. gillnets are $7 \mathrm{~m}$ high).

centration during holomixis) was significantly correlated with fishing depth except for two time series in July (Fig. 3b). Fishing depth decreased with increasing lake trophic status from the late 1950 s to the late 1980 s, and vice versa until the late 2000 s. Fishing depth was related significantly $(P<0.05)$ to standing stock biomass from August to the end of the fishing season in October. The fit $\left(R^{2}\right.$ adj $)$ of these multiple linear regression models varied between 0.2 and 0.4 (Fig. 3a). The best fit was in September, when the partial effects of phosphorus concentration and standing stock biomass were greatest.

The temperature regime experienced by whitefish at the depth fished by gillnets (from the float line to the lead line) during September ranged from 10 to $16^{\circ} \mathrm{C}$ in most years. Since about 1995, the float lines have been set well below the $16^{\circ} \mathrm{C}$ isotherm and the temperature in the layer fished by the gillnets mostly ranged from 8 to $12{ }^{\circ} \mathrm{C}$ (Fig. 4).

\section{Discussion}

Whitefish showed a consistent seasonal pattern in its vertical distribution throughout the study period 1958-2007. However, the rate and extent of downward movement in summer and autumn differed substantially between decades. These differences were related to two factors that influence food supply of whitefish: phosphorous concentration, which is taken as a proxy for average zooplankton biomass (Carpenter et al. 1985) and whitefish standing stock biomass. In years with high food supply, resulting from low standing stock biomass and/or high lake productivity, the fish gathered at shallower depths than in years with low food supply. By the end of the 1990s, whitefish standing stock biomass in ULC was consistently higher than at any other time during the study period (Thomas \& Eckmann 2007). Data on standing stock biomass for the early 2000 s are not yet available, but with phosphorous concentration in ULC returning to oligotrophic levels, it is most likely that food supply for whitefish was consistently low during these years. Whitefish distribution during the last decade was the deepest of all five decades considered in this study.

During winter, when water temperatures drop to around $4{ }^{\circ} \mathrm{C}$ and the abundance of large zooplankton species is low, fish are rather lethargic and foraging activity is minimal (most fish caught have empty stomachs). In April, fish ascend towards the surface and start feeding. They benefit from high zooplankton abundance during the spring plankton bloom and from mild water temperatures. Whitefish stomach fullness is greater at this time than any other period in the growing season (Eckmann et al. 2002). The gradual return to greater depths starts when surface temperature exceeds approximately $12{ }^{\circ} \mathrm{C}$ (Fig. 1). As a cold-adapted species, whitefish avoids high water temperatures, preferring temperatures between 8 and $15^{\circ} \mathrm{C}$ (Alabaster \& Lloyd 1980). Hamrin (1986) reported that adult vendace, Coregonus albula (L.) avoided temperatures in excess of $18{ }^{\circ} \mathrm{C}$ and were therefore distributed in the meta- and hypo-limnion of stratified lakes. Dembinski (1971) found a similar pattern for $C$. albula in Polish lakes, where vendace were distributed at shallow depths from April to July but retreated to the hypolimnion during the summer months. The vertical distribution of lake whitefish in September corresponded to a $10-16^{\circ} \mathrm{C}$ temperature zone, decreasing in the most recent years to $8-12{ }^{\circ} \mathrm{C}$ (Fig. 4).

Ptak and Appenzeller (1998) conducted hydroacoustic surveys in Upper Lake Constance between 1994 and 1996. The seasonal pattern of whitefish vertical distribution recorded corresponded to that observed in the present study, although data for March until June were lacking most probably because the aggregation of fish close to the surface made reliable mapping with the echosounder impossible. The daytime distribution of whitefish recorded was similar to the dusk/dawn distribution described here. High amplitude diel vertical migrations, as reported for several other Coregonus spp. populations (Hrabik et al. 2006; Mehner et al. 2007), are therefore unlikely for ULC whitefish. Hydroacoustic surveys in 2006 and 2007 supported this conclusion (G. Thomas, unpublished data). 
It was concluded that with ongoing warming of the epilimnion, whitefish evade unsuitable high temperatures by distributing within or below the thermocline. The thermocline thus becomes the upper limit of whitefish habitat in summer, inhibiting distribution in shallower depths. The timing of the formation and the rate of the vertical expansion of the thermocline are the results of meteorological conditions. Climate change might therefore be expected to influence vertical distribution of whitefish by changing the depth of the thermocline and thus the upper limit of whitefish distribution in summer. No evidence for this scenario has been recorded so far, because the variable year was significantly correlated to whitefish depth only during months when the thermocline was yet to form (cf. Fig. 3b).

This study demonstrates a significant correlation between lake productivity and whitefish vertical distribution, assessed in terms of fishing depth. This correlation might be a direct effect of lake trophic status on fish distribution, mediated by prey abundance. Alternatively, the influence might be indirect, via changes in the light penetration as a result of changes in lake productivity. At first glance, changes in Secchi depth across the year show a pattern similar to that of the whitefish's vertical distribution (Fig. 5). During the summer months, Secchi depth is the shallowest in August and increases towards the end of the year. Whitefish, however, start to descend earlier in the year and end their downward movement by the beginning of September, when Secchi depth is still increasing. Furthermore, fishing depth was not correlated with Secchi depth for the summer months, similar

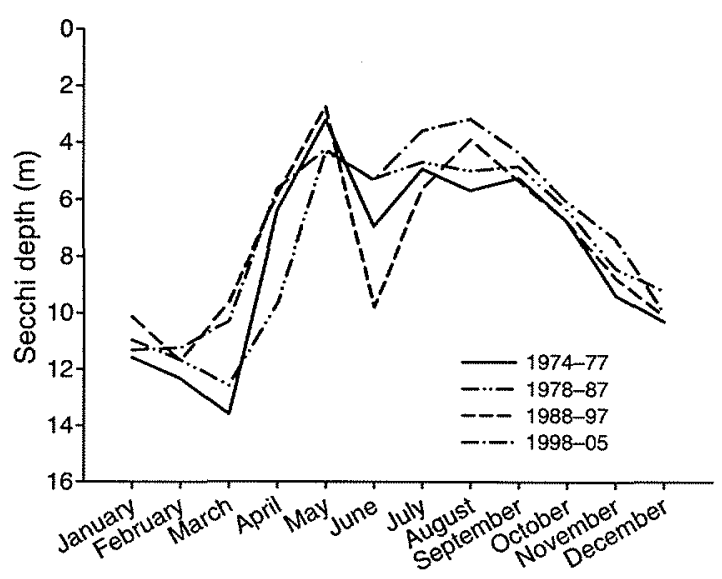

Figure 5. Seasonal course of Secchi depth in ULC between 1974 and 2005 averaged over four time intervals. Note different lengths of time intervals due to limited data availability. to the findings for Lake Stechlin vendace (Mehner et al. 2007). Thus, there are no indications that light penetration is the main factor influencing whitefish vertical distribution and this hypothesis was rejected.

The most plausible explanation for the observed vertical distribution patterns of whitefish in summer and autumn is lake productivity, which influences whitefish via zooplankton abundance, together with standing stock biomass. In years with high supply of zooplankton, whitefish seem to be distributed within or directly below the thermocline, where they benefit from low water temperatures and the best of the light during the gloomy hours of the day, when feeding activity is greatest (Eckmann et al. 2002). When fish abundance is high and/or zooplankton abundance low, competition for food increases at the preferred depth and fish are obliged to reassess their habitat choice (Kacelnik et al. 1992). A proportion of the population will probably move to greater depth, distributing along the resource gradient in proportion to the actual pattern of resource availability, thereby reducing the overall pressure of intraspecific competition (Ward et al. 2006). The move to greater depth might imply lower foraging efficiency because of reduced light intensity (Robinson \& Tash 1979). The trade-off between intraspecific competition pressure and lightdependent foraging efficiency is likely to be the principle factor controlling the vertical distribution pattern of pelagic zooplanktivorous whitefish in ULC, in line with the ideal free distribution theory. The increase of mean fishing depth, in parallel with decreasing lake productivity and/or increasing standing stock biomass, may not necessarily represent a shift of the entire population to greater depth but rather a wider spread of the fish towards the hypolimnion.

An alternative explanation is based on a study on salmonids, Salmo spp., which found starving individuals seek cooler (deeper) waters to reduce metabolic costs (Javaid \& Anderson 1967). In this scenario, mean fishing depth would be greater in years of low food supply, while the vertical spread of the fish distribution might remain the same. The September fishing depth distribution observed in the current study (Fig. 4) indicated that in the early $2000 \mathrm{~s}$, whitefish were harvested from greater depths, where temperature was about $4^{\circ} \mathrm{C}$ lower, than in the period before 1990. As they stand, the results do not allow a decision on which of the two alternatives, albeit they are not mutually exclusive explanations for a deeper distribution of whitefish, is more plausible. In both scenarios, fish are located deeper and consequently at lower water temperatures when food supply is low. 
This study found that changes in the vertical distribution of whitefish in ULC can be linked to changes in environmental conditions that control zooplankton food supply. Although the ultimate mechanism(s) remain unresolved, the results might be useful for the future management of the whitefish fishery. Phosphorous concentration has decreased to such a low level in recent years, from which a further decrease is unlikely, that changes in fishing depth during late summer may be taken as a proxy for whitefish standing stock biomass.

\section{Acknowledgments}

Thanks to the Regierungspräsidium Tübingen and the Institute for Lake Research, Langenargen for providing $u$ s the monthly reports of fishery wardens. Temperature and Secchi depth data are from the International Commission for the Protection of Lake Constance (IGKB) and were provided by Robert Obad (Institute for Lake Research, Langenargen). Amy-Jane Beer corrected the English. This study was supported within the priority program AQUASHIFT by the Deutsche Forschungsgemeinschaft (EC 146/3-1).

\section{References}

Aksnes D.L., Nejstgaard J., Soedberg E. \& Sornes T. (2004) Optical control of fish and zooplankton populations. Limnology and Oceanography 49, 233-238.

Alabaster J.S. \& Lloyd R. (1980) Water Quality Criteria for Freshwater Fish. London: Butterworth, 297 pp.

Arlinghaus R., Mehner T. \& Cowx I.G. (2002) Reconciling traditional inland fisheries management and sustainability in industrialized countries, with emphasis on Europe. Fish and Fisheries 3, 261-316.

Bäuerle E. \& Gaedke U. (1998) Lake Constance, characterization of an ecosystem in transition. Archiv für Hydrobiologie 53, 610 .

Becker M. \& Eckmann R. (1992) Plankton selection by pelagic European whitefish in Lake Constance: dependency on season and time of day. Polskie Archiwum Hydrobiologii 39, 393-402.

Carpenter S.R, Kitchell J.F. \& Hodgson J.R. (1985) Cascading trophic interactions and lake productivity. BioScience 35, 634-639.

Dembinski W. (1971) Vertical distribution of vendace Coregonus albula $\mathrm{L}$. and other pelagic fish species in some Polish lakes. Journal of Fish Biology 3, 341-357.

Eckmann R., Becker M. \& Schmid M. (2002) Estimating food consumption by a heavily fished stock of zooplanktivorous Coregonus lavaretus. Transactions of the American Fisheries Society 131, 946-955.
Fernöa A., Huseb I., Juellc J.E. \& Bjordalc Å. (1995) Vertical distribution of Atlantic salmon (Salmo salar L.) in net pens: trade-off between surface light avoidance and food attraction. Aquaculture 132, 285-296.

Fretwell S.D. (1972) Populations in a Seasonal Environment. Princeton, NJ: Princeton University Press, 217 pp.

Hamrin S. (1986) Vertical distribution and habitat partioning between different size classes of vendace, Coregonus albula, in thermally stratified lakes. Canadian Journal of Fisheries and Aquatic Sciences 43, 1617-1625.

Horak D.L. \& Tanner H.A. (1964) The use of vertical gill nets in studying fish depth distributions, Horse-tooth Reservoir; Colorado. Transactions of the American Fisheries Society 93, 137-145.

Hrabik T.R., Jensen O.P., Martell S.J.D., Walters C.J. \& Kitchell J.F. (2006) Diel vertical migration in the Lake Superior pelagic community. I. Changes in vertical migration of coregonids in response to varying predation risk. Canadian Journal of Fisheries and Aquatic Sciences 63, 2286-2295.

IGKB (2009) Limnologischer Zustand des Bodensees. Bericht Nr. 36. Internationale Gewässerschutzkommission für den Bodensee. 95 pp.

Javaid M.Y. \& Anderson J.M. (1967) Thermal acclimation and temperature selection in Atlantic salmon, Salmo salar and rainbow trout, Salmo gairdneri. Journal of the Fisheries Research Board of Canada 93, 137-145.

Kacelnik A., Krebs J.R. \& Bernstein C. (1992) The ideal free distribution and predator-prey populations. Trends in Ecology and Evolution 7, 50-55.

Mackinson S. (2001) Integrating local and scientific knowledge: an example in fisheries science. Environmental Management 27, 533-545.

Mehner T., Kasprzak P. \& Hölker F. (2007) Exploring ultimate hypotheses to predict diel vertical migrations in coregonid fish. Canadian Journal of Fisheries and Aquatic Sciences 64, 874-886.

Mittelbach G.G. (1981) Foraging efficiency and body size: a study of optimal diet and habitat use by bluegills. Ecology 62, 1370-1386.

Nümann W. (1964) Die Eutrophierung des Bodensees, die Zunahme der Barsche und die intensive Befischung als Ursache für den rapiden Rückgang der Blaufelchenfänge. Allgemeine Fischerei-Zeitung 10, 308-311.

Ptak J.K. \& Appenzeller A.R. (1998) Size, depth, and frequency of pelagic Lake Constance whitefish (Coregonus lavaretus L.) shoals during the seasons: a hydroacoustic study. Archiv für Hydrobiologie Special Issues Advances in Limnology 50, 237-248.

Robinson F.W. \& Tash J.C. (1979) Feeding by Arizona trout (Salmo apache) and brown trout (Salmo trutta) at different light intensities. Environmental Biology of Fishes 4, 363368 . 
Rösch R. (2003) Veränderungen in der Felchenfischerei im Bodensee-Obersee 1990-2003. Fischereiinformationen aus Baden-Württemberg 19, 19-24.

Rudstam L.G. \& Magnuson J.J. (1985) Predicting the vertical distribution of fish poulations: analysis of cisco, Coregonus artedii, and yellow perch, Perca flavescens. Canadian Journal of Fisheries and Aquatic Sciences 42, 1178-1188.

Thomas G. \& Eckmann R. (2007) The influence of eutrophication and population biomass on common whitefish (Coregonus lavaretus) growth - the Lake Constance example revisited. Canadian Journal of Fisheries and Aquatic Sciences 64, 402-410.

Ward A.J.W., Webster M.M. \& Hart P.J.B. (2006) Intraspecific food competition in fishes. Fish and Fisheries 7, 231-261.

Werner E.E. \& Hall D.J. (1988) Ontogenetic habitat shifts in bluegill: the foraging rate-predation risk trade-off. Ecology 69, 1540-1548.

Werner E.E., Mittelbach G.G., Hall D.J. \& Gilliam J.F. (1983) Experimental tests of habitat use in fish: the role of relative habitat profitability. Ecology 64, 1525-1539. 